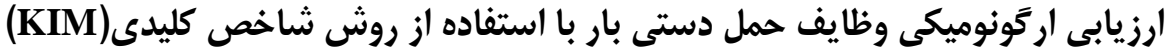

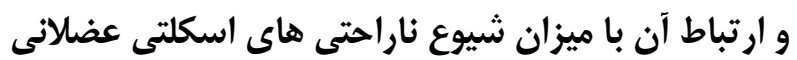

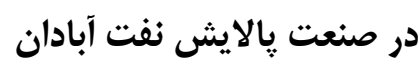

$$
\text { جعفر اكبرى'، سيدمهدى موسوى كوتى'، مقداد كاظمى'، روح الدين مرادى راد ** }
$$

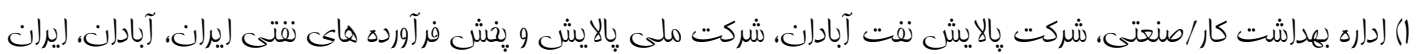

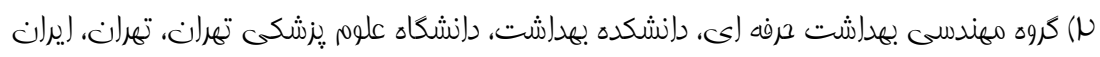

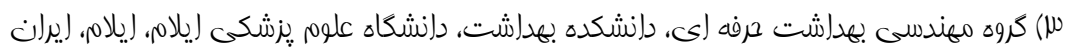

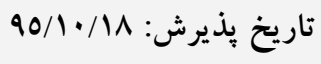

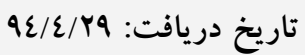

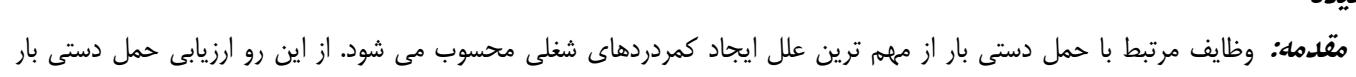

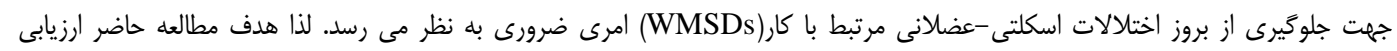

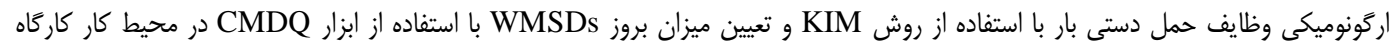

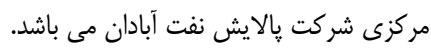

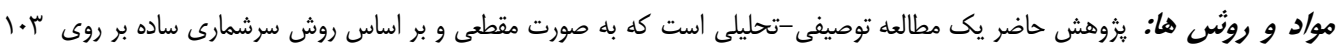

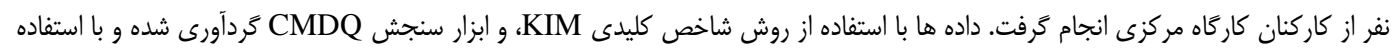

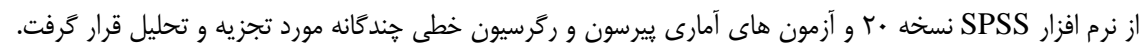

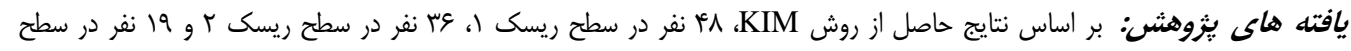

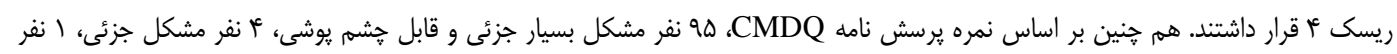

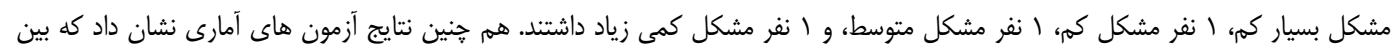

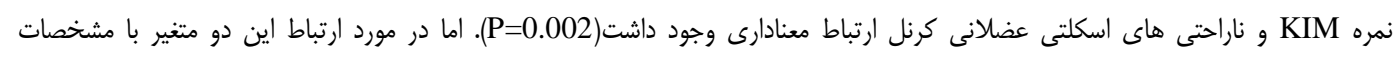

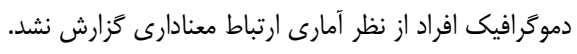

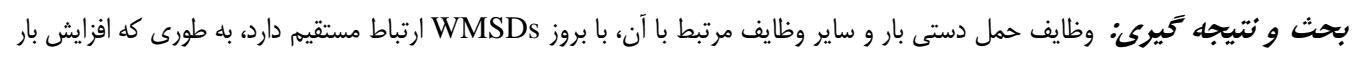

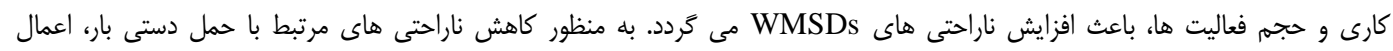

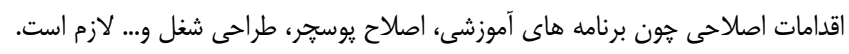

وازهه هاى كليدى: حمل دستى بار، اختلالات اسكلتى عضلانى مرتبط با كار، روش شاخص كليدى KIM، يرسش نامه ناراحتى

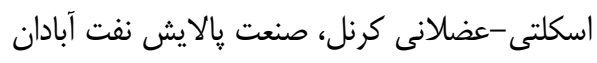

* نويسنده مسئول: اداره بهداشت كار /صنعتى، شركت پِالايش نفت آبادان، شركت ملى پالايش و بخش فرآورده هاى نفتى ايران، آبادان، ايران Email: r.moradi50@yahoo.com

Copyright (C) 2018 Journal of Ilam University of Medical Science. This is an open-access article distributed under the terms of the Creative Commons Attribution international 4.0 International License (https://creativecommons.org/licenses/by-nc/4.0/) which permits copy and redistribute the material, in any medium or format, provided the original work is properly cited. 
دستى بار را به عنوان يكى از مهمه ترين عوامل ايجاد

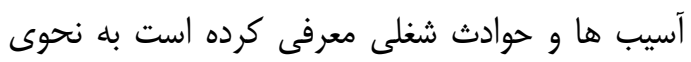

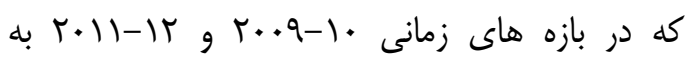
ترتيب به عنوان عامل عس و كس درصد از علل حوادث

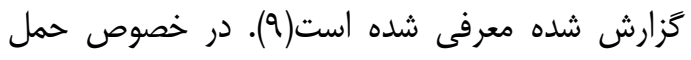

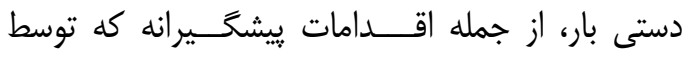

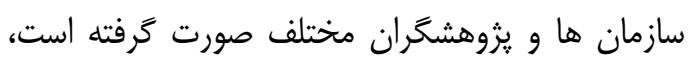

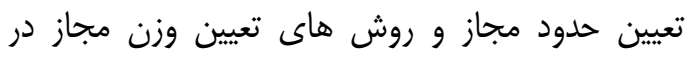
وظايف حمل دستى بار بوده است. از جمله اين روش هان ولهين

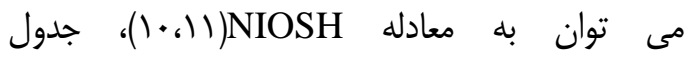

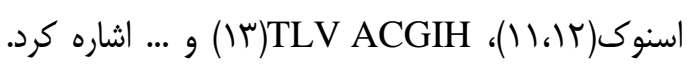
يكى از كامل ترين روش هاى ارزيابى اركونومى در اين

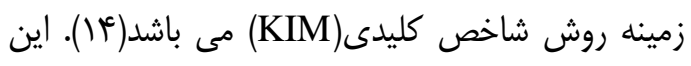
روش به منظور ارزيابى مواجهاه مخاطرات اسكلتى

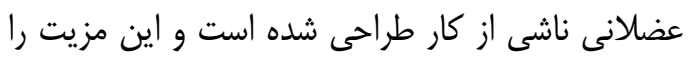

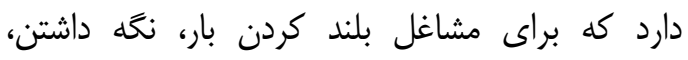

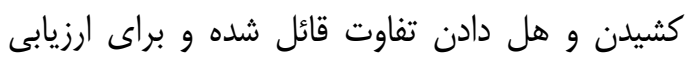

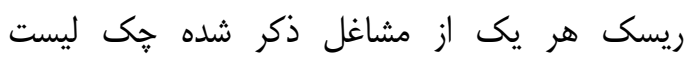

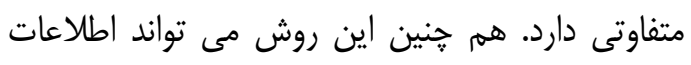

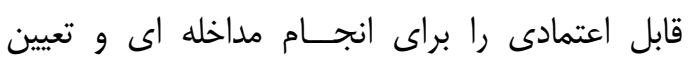

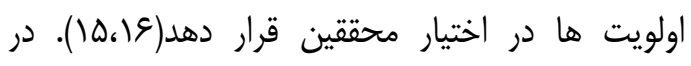

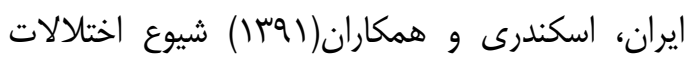
اسكلتى عضلانى و ريسك شغلى حمل دستى بار

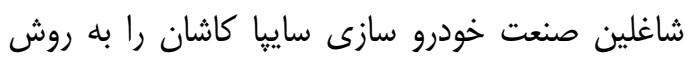
شاخص كليدى مورد بررسى قرار دادند. نتايج اين مطالعه نشان داد كه عمده ترين مشكل در شاغلين، مربوط به وضعيت بدنى نامطلوب، حمل دستى بار و و

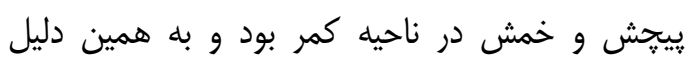
اختلالات اسكلتى-عضلانى در ناحيه كمر بيشترين

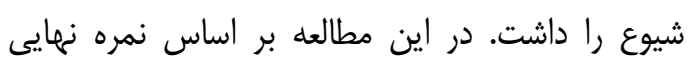

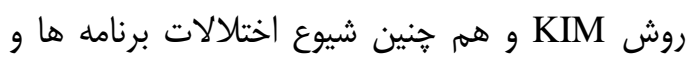
اقدامات كنترلى تعريف شد(ه) (1).

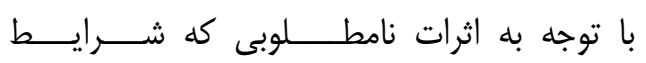

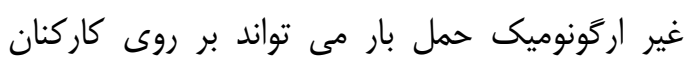

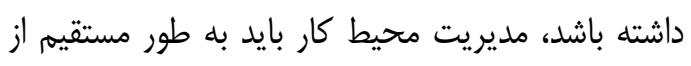
سيستم برقرارى تناسب بين نيازمندى هاى وظائ

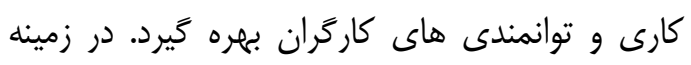

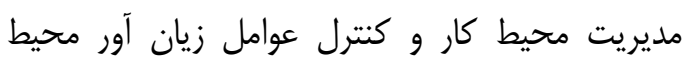

\section{مقدمه - 20 - مقد}

اختلالات اسكــلتى -عضلانى شــامل؛ اختلالات

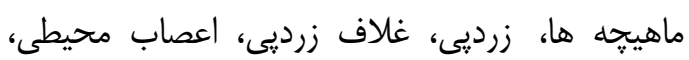

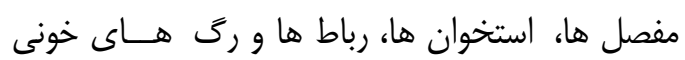

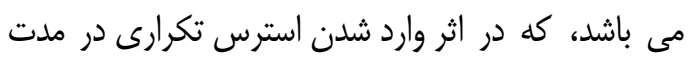

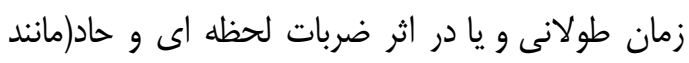

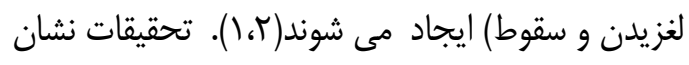

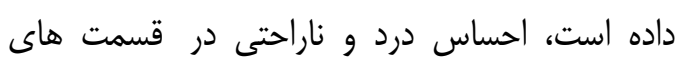

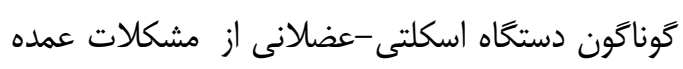

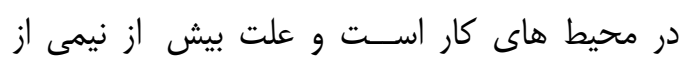

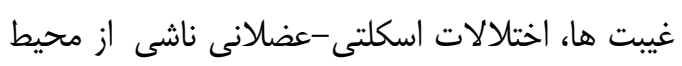

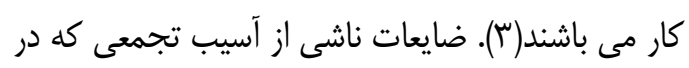

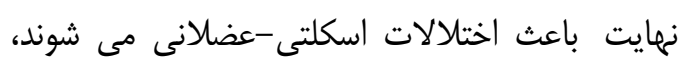

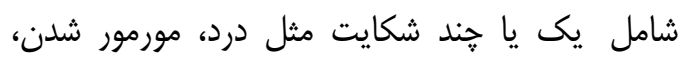

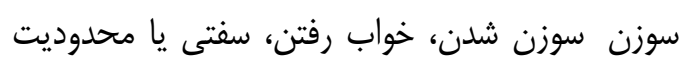

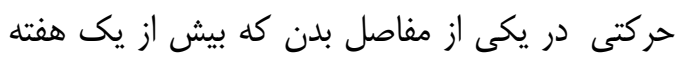

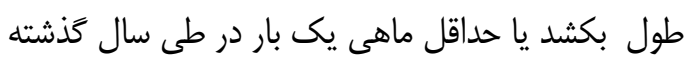

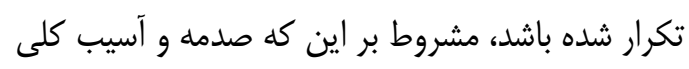
براى مفصل مربوط وجود نداشته و علايم به طور

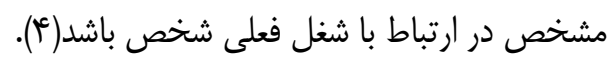

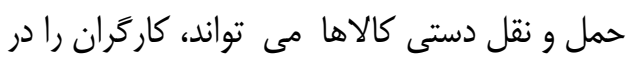

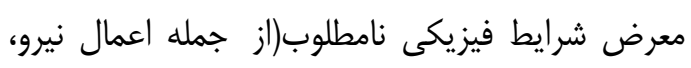

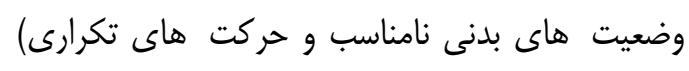

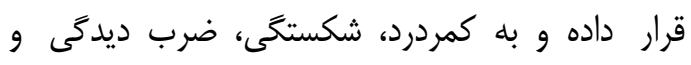

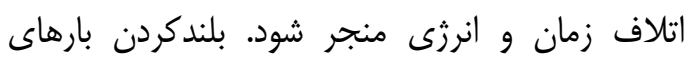

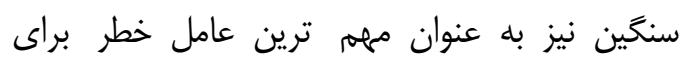

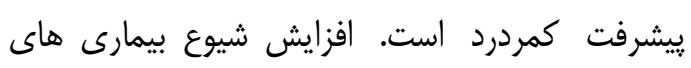

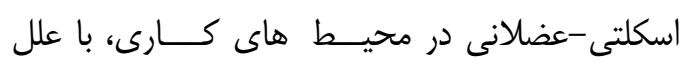

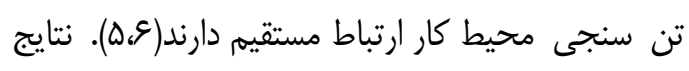

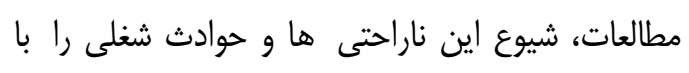

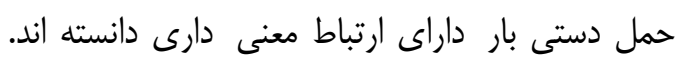

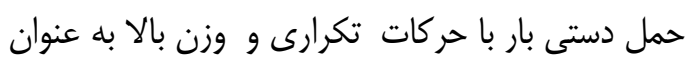

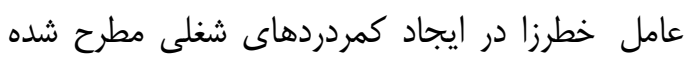

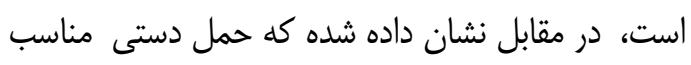

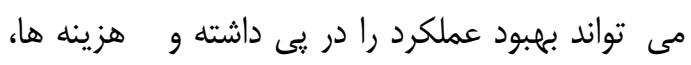

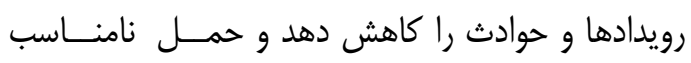

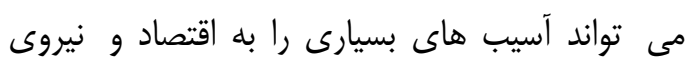

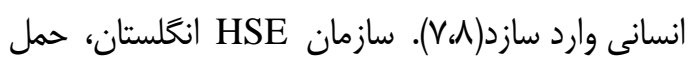


به منظور ارزيابى شرايط كارى در وظايف مرتبط با حمل دستى بار، يك روش جديد به نام روش شاخص دابع دابع

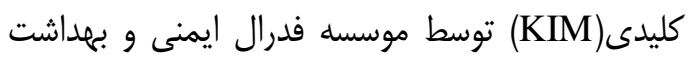

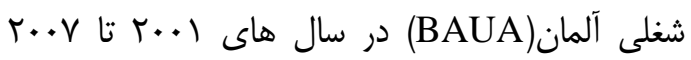

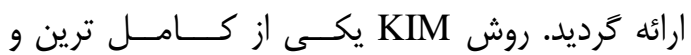
معتبرترين روش هاى ارزيابى وظايف دستى و وظايف حمل بار مى باشد كه داراى سه برك متفاوت معى معى باشد

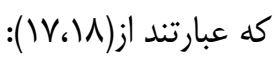
KIM-LHC (1) اين روش را مى توان در وظايف بلند كردن بار، نكةه داشتن بار و حمل كردن بار به كار

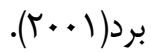

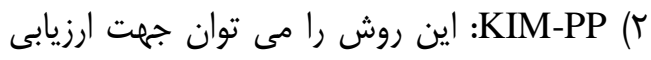

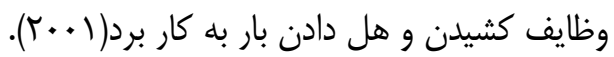

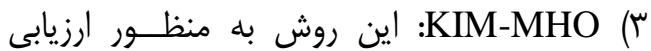

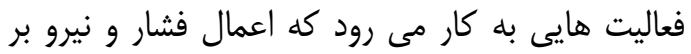
روى بازو-دست-انخشتان در هنغام كار بر روى روان اشياء

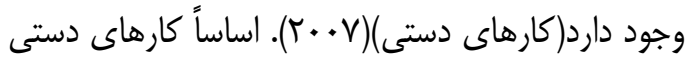
به أ دسته طبقه بندى مى شوند: الف) كـارهاى دقيـق: كارهايى كه نياز به دقت بله

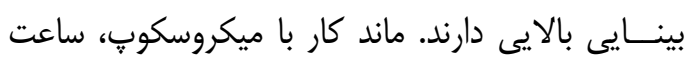

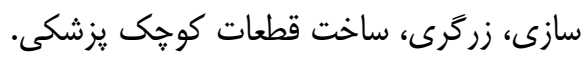
ب) كارهاى حركتى همراه با دقت بينايى بالا: مانند كار دوخت، مونتاز قطعات الكتريكى كوجى هاره، مونتاز صفحه نمايش و سيستم هاى حس كر.

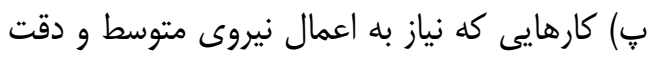
بينايى معمولى دارند: مانند توليد لوازم خانكىى، بسته بندى مواد غذايى، توليد شيرينى و ...

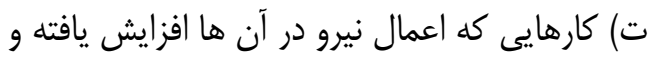
نياز به دقت بينايى معمولى دارند. مانند سراجى، برش اعنى كوشت، توليد مبلمان و ... در اين روش ارزيابى و محاسبه امتياز نهايى بدين

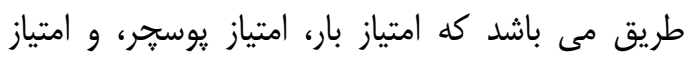

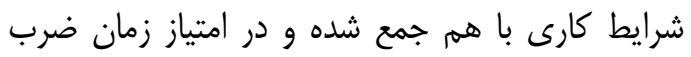
مى شود. در نهايت تعريف و اجراى اقدام اصلاحى با

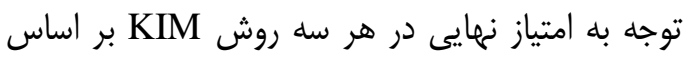
جدول شماره ا ( عا) مشخص مى شود:
كار، ارزيابى و بررسى ريسك فاكتورهاى محيط كار به عنوان קايه اى جهت اقدامات كنترلى و مداخله ایى محيط كار محسوب مى شود. بنا بر اين شناسايى و وايه

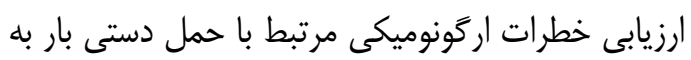

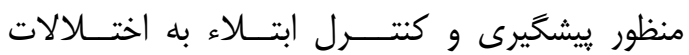
اسكلتى-عضلانى محيط كار امرى ضرورى مى باشد.

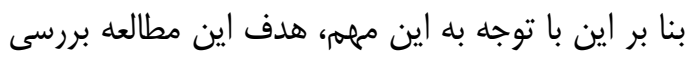
و ارزيابى وظايف حمل دستى بار و ارتباط آن با بروز

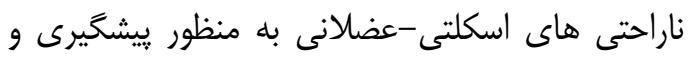
كنترل ريسك فاكتورهاى شغلى محيط كار و شغل كاركنان كاركاه مركزى شركت يالايش نفت آبادان بود.

\section{مواد و روش هان كاركا مران}

تحقيق حاضر يك مطالعه توصيفى -تحليلى است.

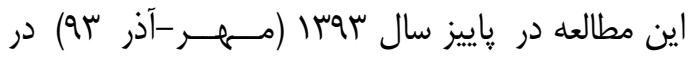
شاب هاى مختلف كار كاه مركزى شركت يالايش نفت

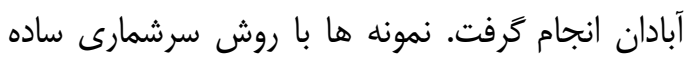
انتخاب شده كه در نهايت تعداد س.ا نفر آنهام از كاركنان شابٍ هاى اين كاركاه در مطالعه شركت كردند. افراد مورد مطالعه از نظر سابقه بيمارى هاى اثركذار بر

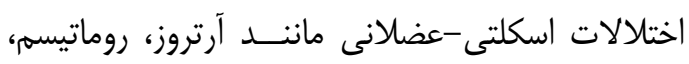

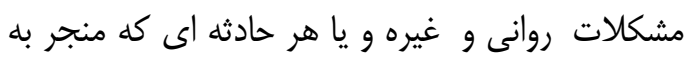

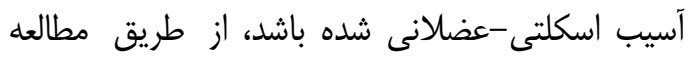
يرونده هاى يزشكى و سوابق كارى مورد بررسى قرار كرفتند. ديخر معيارهاى ورود افراد در مطالعاله انجام

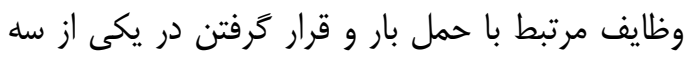
معيار مورد بررسى روش KIM (شامل KIM-LHC، KIM-PP، كIM-MHO)، و هم קنين داشتن حداقل يك سال سابقه كار در شغل مورد نظر بود.

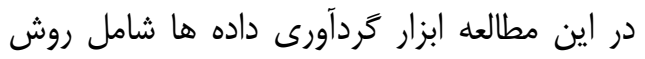
شاخص كليدى(KIM) جهت بررسى وظايف حمل دستى بار و يك يرسش نامه متشكل از ويزگ جلى هاى

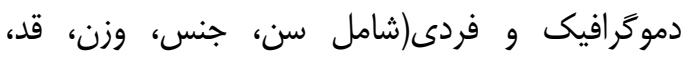

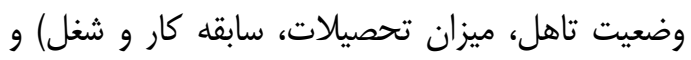

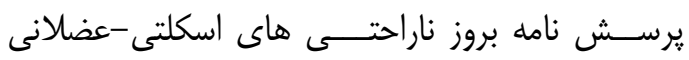
كرنل(CMDQ) بود. 


\begin{tabular}{|c|c|c|}
\hline توصيف & 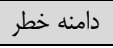 & امتياز نهايى \\
\hline مقدار بار كم. بروز بار فيزيكى اضافى بعيد به نظر مى رسد. & 1 & $<1$ \\
\hline 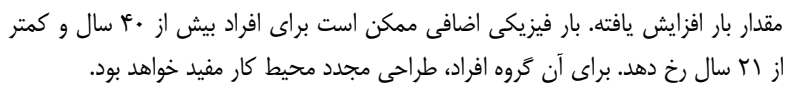 & r & 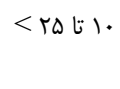 \\
\hline 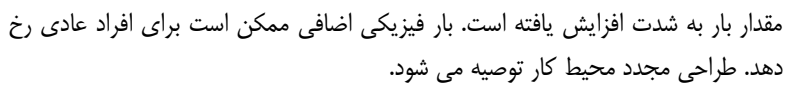 & r & $<\Delta \cdot r_{\Delta}$ \\
\hline ضرورى ميى باشد. بار بالا. فيزيكى اضافى به احتمال زياد رخ مى دهد. طراحى مجدد محيط كار & r & $\geq \Delta$. \\
\hline
\end{tabular}

تفسير ناراحتى هاى اسكلتى-عضلانى بر اساس نمره

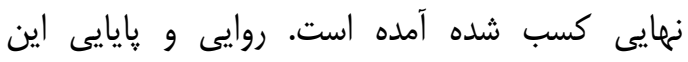

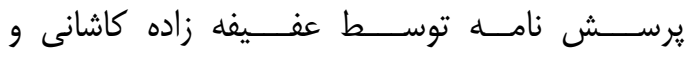

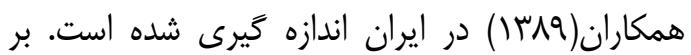
اين اساس در تحليل روايى يرسش نامه براى قسمت

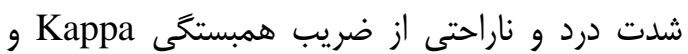

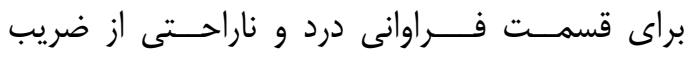
همبستخى اسبيرمن استفاده شده است. در تحليل پإيايى يرسش نامه، ضريب آلفاى كرونباخ ع19/. محاسبه شده است. ضريب آلفاى كرونباخ در هر سه به بخش

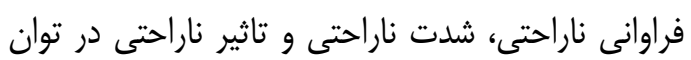

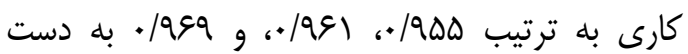

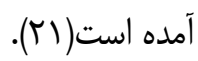

يـرسـش نامــــهـ ناراحســـى اسكلتى -عضلانى

كرنل( Cornell Musculoskeletal Discomfort (Questionnaire

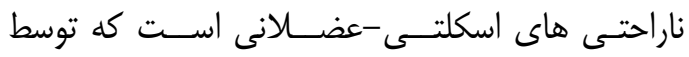
يروفسور Alan Hedge و همكاران در سال 1999 تدوين شده است. اين يرسش نامه در سه مرحله

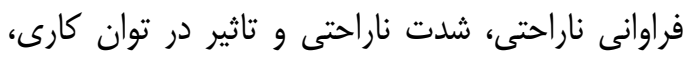
در هفته كارى كذشته تنظيم شده است كه داراى نقشاته

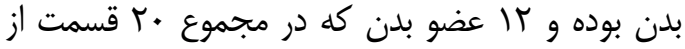

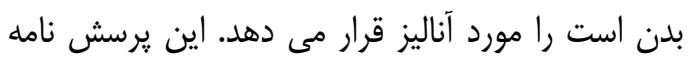

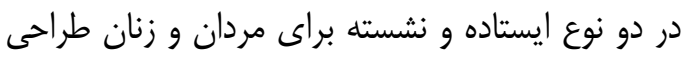

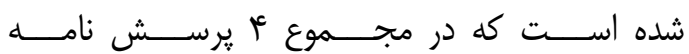
مى شود(·r،19). در جدول شماره r گروه بندى و

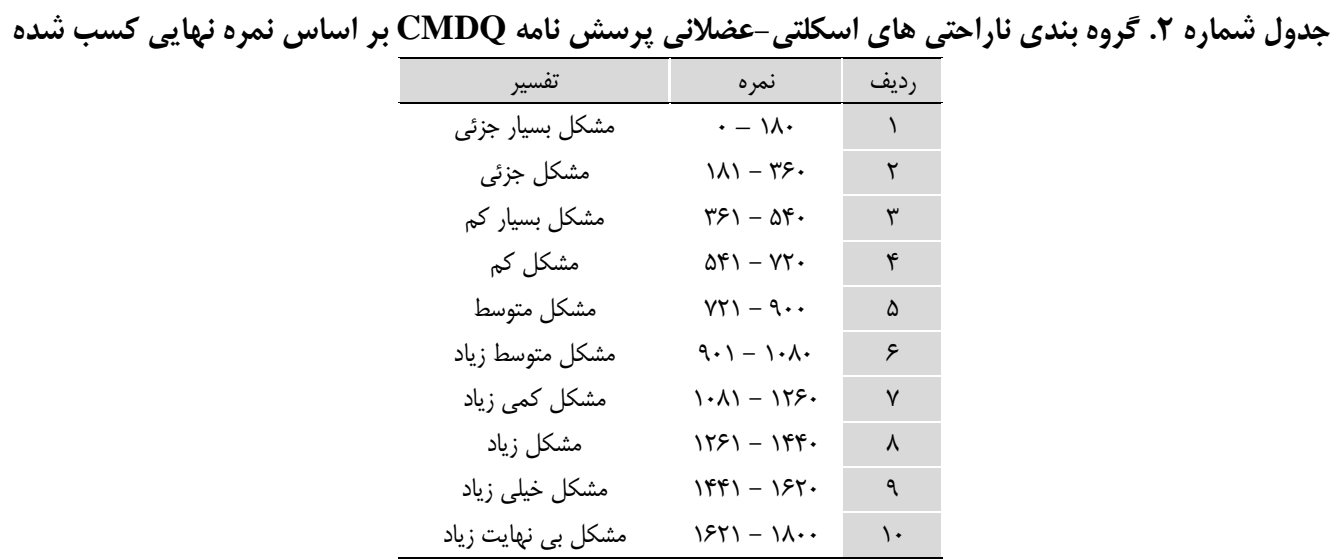

حاصل از روش KIM با متغيرهاى دموكرافيك مورد

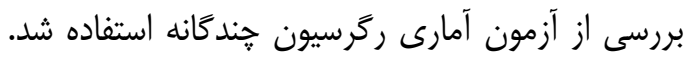

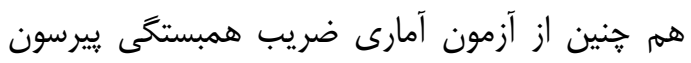
به منظور تعيين رابطه بين ناراحتى هاى اسكلتى -

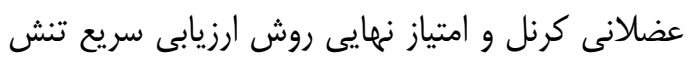

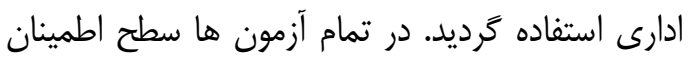
ه9 درصد در نظر ترفته شد.
داده هاى مطالعه با استفاده از نرم افزار

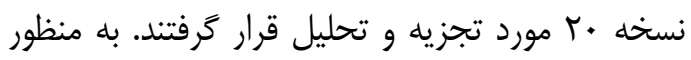

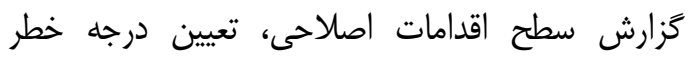

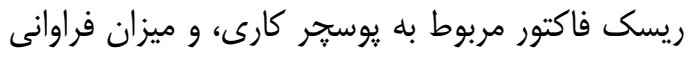

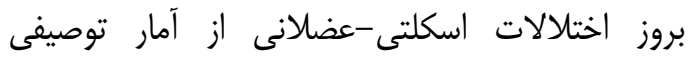

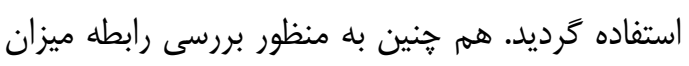
بروز ناراحتى هاى اسكلتى-عضلانى و امتياز نهايى بردي 


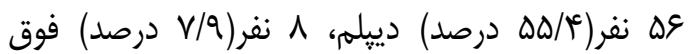

يافته هاى يزوهش

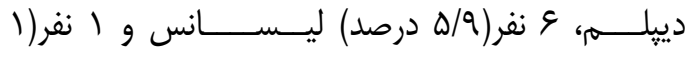

افراد مورد مطالعه شامل س+1 نفر مرد با سلامتى "يكى

درصــد) فوق ليســــانس بودنـــــــ ساير مشخصات كامل و بدون هيج گونه بيمارى بودند. عس/آ درصد از مورد

دموگرافيك افراد مورد مطالعه در جدول شماره س بر

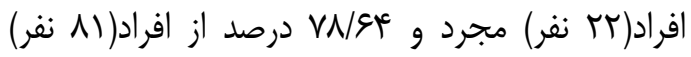

حسب ميانگين، انحراف معيار، حداقل و حداكثر نشان

متاهل بودند. هم جنين بر حسب تحصيلات، .

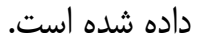

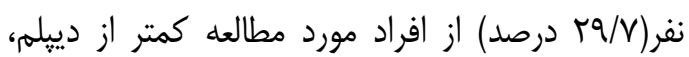

\begin{tabular}{|c|c|c|c|c|}
\hline حداكثر & حداقل & انحراف معيار & ميانكين & جدول سماره I. \\
\hline$\Delta \Lambda$ & r & $1.1 \cdot 0$ & $\mu q / \varsigma \Delta$ & سن(سال) \\
\hline ع & 1 & १/६६ & $\mid r / \Lambda F$ & سابقه كار(سال) \\
\hline 119 & q. & 1.110 & $I V T / N G$ & قد(سانتى متر) \\
\hline ir. & $\Delta r$ & $|r / 4|$ & $\mathrm{va} / \mathrm{Ar}$ & وزن(كيلوكرم) \\
\hline rq/ه & $18 / 99$ & r/R & $r \varepsilon / 0$. & BMI (كبلو كرم/متر مربع) \\
\hline
\end{tabular}

ميانَين نمره KIM در افراد مورد مطالعه: در اين

مطالعه، با مصاحبه و تعيين وظايف هر شغل، انواع مشاغل مورد بررسى در گروه هاى مختلف ارزيابى شده و با يكى از روش هاى سه گَانه ذكر شده مورد بررسى

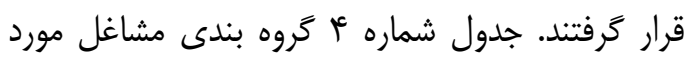
بررسى را در هر يك از روش هاى ســـه كانه نشـــان مى دهد.
نتايج اين مطالعه نشان داد كه ^^ نفر( ع/عץ درصد) از افراد مورد مطالعه در گروه \بار كمه قرار گرفتند. هم جنين مشخص شد كه عس نفر(ه/ مورد مطالعه در رده بار افزايش يافته و 19 نفر(أF/N درصد) افراد در رده ميزان بار بالا قرار گرفتند. جدول شماره ه فراوانى و درصد نمره به دست آمده از روش را براى افراد مورد مطالعه نشان مى دهد. KIM

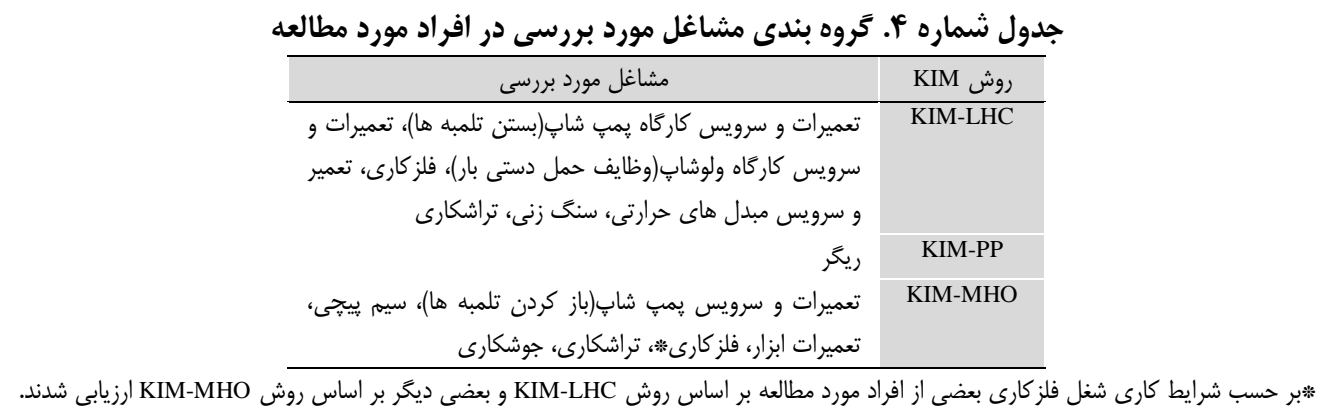

\begin{tabular}{|c|c|c|}
\hline | مرصد & 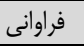 & KIM كروه \\
\hline $\mid 9 / 4$ & is & بار كم|•l> \\
\hline$r \mu / Q D$ & צ" & بار افزايش يافته(بين • ا تا Tه) \\
\hline$\cdot$ & . & بار به شدت افزايش يافته(بين مr تا •ه) \\
\hline W/Fe & 19 & 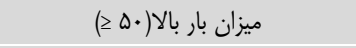 \\
\hline $1 .$. & $1 \cdot r$ & كل \\
\hline
\end{tabular}

ميزان ناراحتى در rا ناحيه اسكلتى عضلانى شامل؛ گردن، شانه ها، قسمت فوقانى گُشت، بازوها، قسمت تحتانى ڤشت، ساعدها، مج دست ها، باسن، ران ها،
ميانَين نمره ناراحتى هاى اسكلتى عضلانى در

افراد مورد مطالعه: به منظور تعيين نمره نهايى ميزان

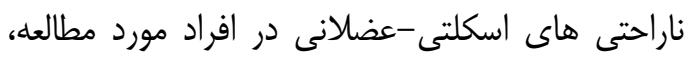




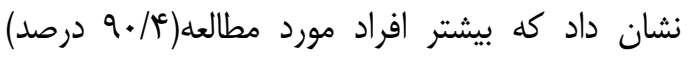

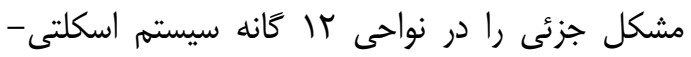

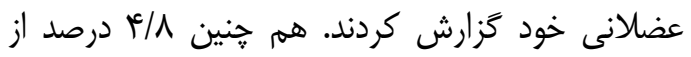

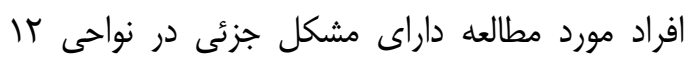

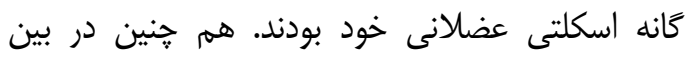

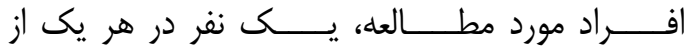

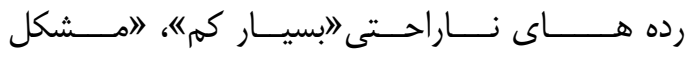
متوسط"، "مشكل كم" و "امشكل كمى زياده قرار كرفتند.

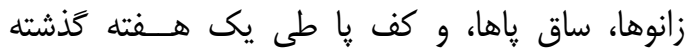

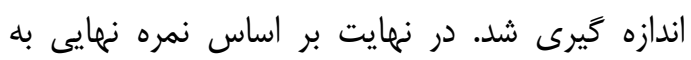

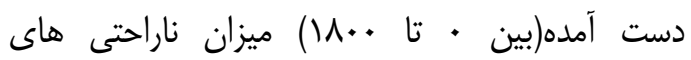

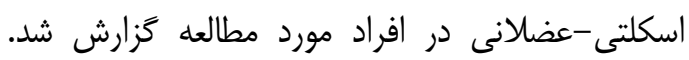
نمره بندى يرسش نامه CMDQ بر اساس ميزان ناراحتى در جدول شماره ه آمده است( •r، (19).

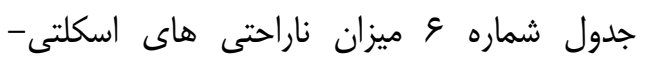
عضلانى را بر اساس فراوانى و درصد در افراد مورد مطالعه نشان مى دهد. نتايج حاصل از خودگزارشى افراد درص دراد

جدول شماره צ. فراوانى و درصد نمره ناراحتى هاى اسكلتى -عضلانى با استفاده از ابزار CMDQ در افراد مورد مطالعه

\begin{tabular}{|c|c|c|}
\hline درصد & فراوانى & گروه ناراحتى هاى اسكلتى -عضلانى \\
\hline $9 . / 4$ & 90 & مشكل بسيار جزئى \\
\hline$r / \Lambda$ & f & مشكل جزئى \\
\hline $1 / r$ & 1 & مشكل بسيار كم \\
\hline $1 / \pi$ & 1 & مشكل كم \\
\hline $1 / r$ & 1 & مشكل متوسط \\
\hline · & - & مشكل متوسط زياد \\
\hline $1 / \pi$ & 1 & مشكل كمى زياد \\
\hline . & . & مشكل زياد \\
\hline . & . & مشكل خيلى زياد \\
\hline$\cdot$ & . & مشكل بى نهايت زياد \\
\hline $1 \cdots$ & $1 \cdot r$ & كل \\
\hline
\end{tabular}

BMI

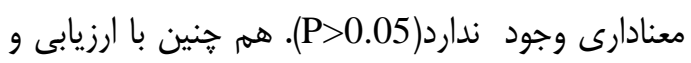

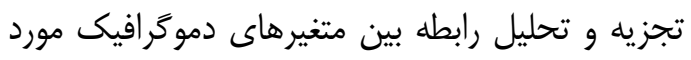

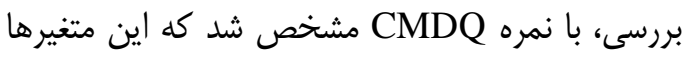
با ناراحتى هاى اسكلتى-عضلانى از نظر آمارى رابطه معنادارى نداشتند(P>0.05).

\section{بحث و نتيجه كيرى}

حمل دستى بارهاى سنخَين و انجام فعاليت هاى

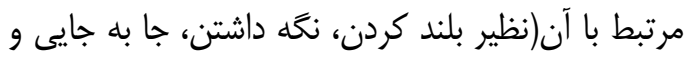

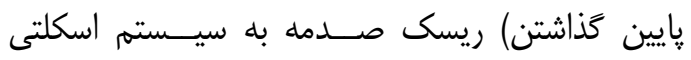

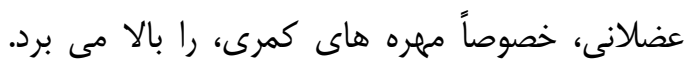

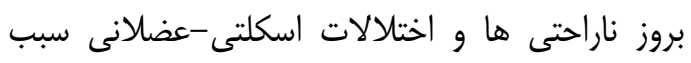

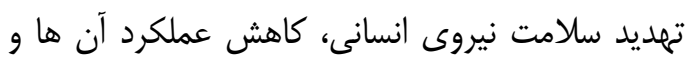

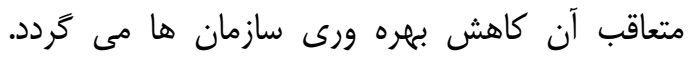
هدف از انجام اين مطالعه، بررسى وظايف مرتبط بـ بان حمل دستى بار و سطح ريسك اين وظايف بران براى

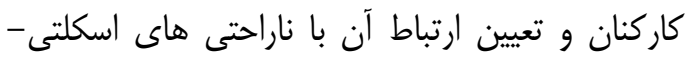

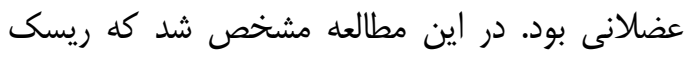

رابطه بين متغيرهاى مورد بررسى در افراد مورد مطالعه: نتايج حاصل از تجزيه و تحليل ارتباط بين نمره

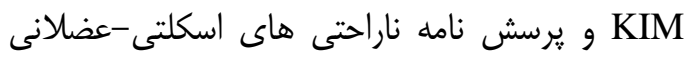

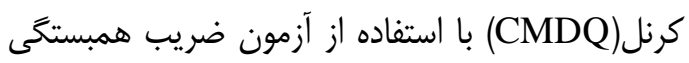
ييرسون نشان داد كه بين نمره KIM و نمره CMDQ

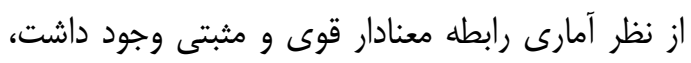

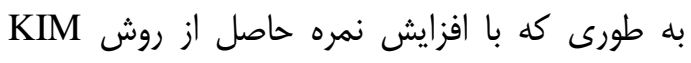

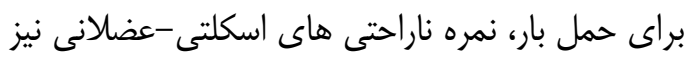

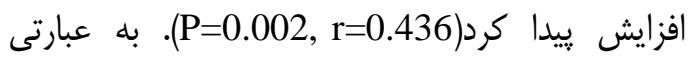

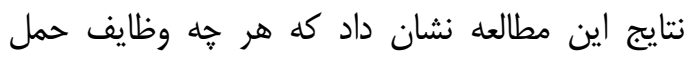
دستى بار و ساير وظايف عملياتى محوله در شرايط بدترى قرار داشتند، افراد درصد بالاترى از نار احتى هائى هاى داى دائ

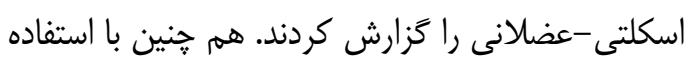

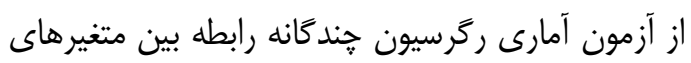

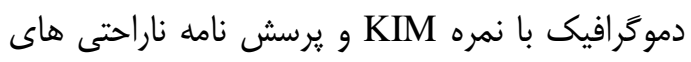
اسكلتى-عضلانى كرنل(CMDQ) مورد ارزيابى قرار

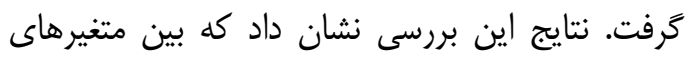

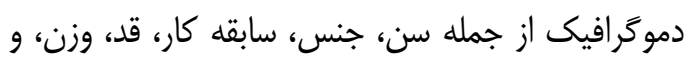


افراد در وضعيت بار كم قرار گرفتند. بر اين اساس، بروز

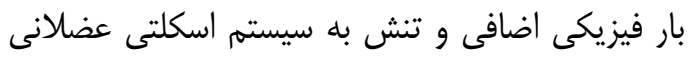

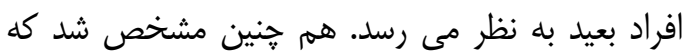

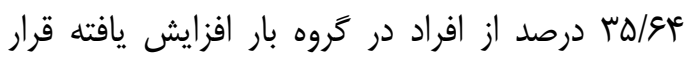

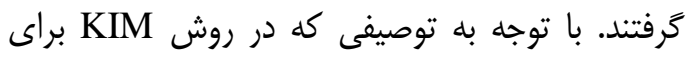

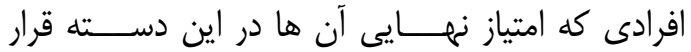
مى كيرد مى توان نتيجه كرفت كه بر اساس نمره كسب شده، بار فيزيكى اضافى ممكن است براى إنى افراد

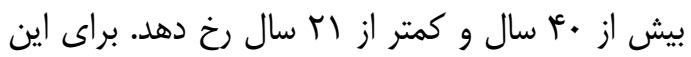
كونه افراد، طراحى مجدد محيط كار ممكن است مفيد

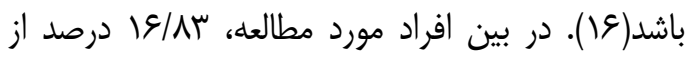

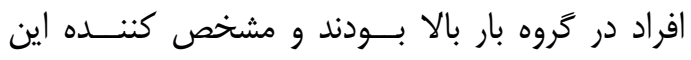

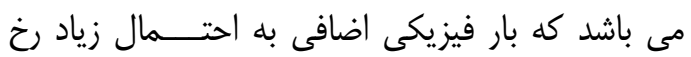
مى دهد. در اين گَونه مشاغل طراحى مجدد كار بار ضرورى مى باشد. بر اساس مطالعه اى كه اسكندرى و

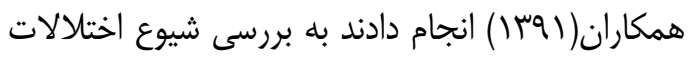

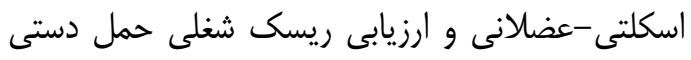
بار شاغلين صنعت خودروسازى ساييا كاشان با استفاده از روش شاخص كليدى(KIM) يرداختند(ها). برخلاف مطالعه حاضر كه شيوع ناراحتى ها در آن بسيار پإيين بود، اين مطالعه نشان داد كه بيشترين شيوع اختلالات بين گروه هاى شغلى مورد بررسى در نواحى كمر و

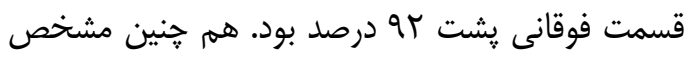

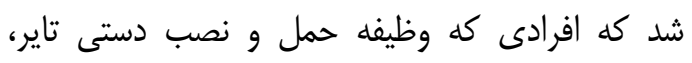

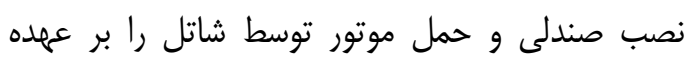

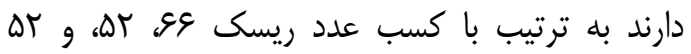
داراى بيشترين ريسك بودند. تعداد س نفر سطح ريسك

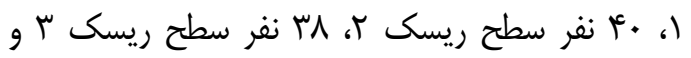

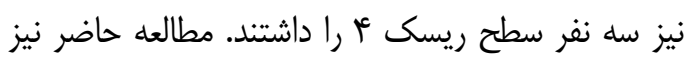
نشان داد كه بين شدت ناراحتى ها و اختلالات رنات اسكلتى-عضلانى مرتبط با كار و شدت بار كار كارى دار در

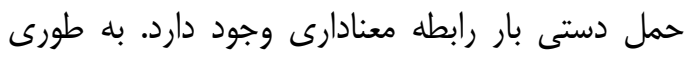

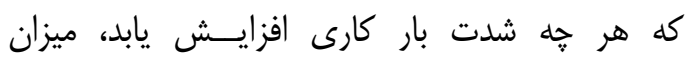

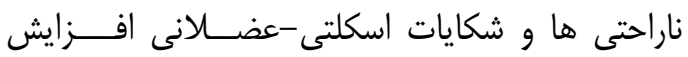

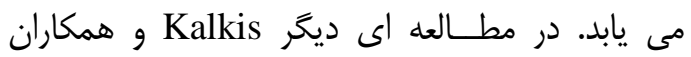

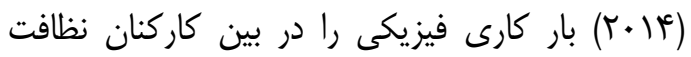
جى هتل با استفاده از روش شاخص كليدى(KIM)

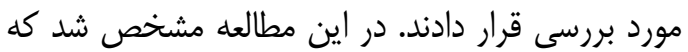

ابتلاء به اختلالات اسكلتى -عضلانى در مقايسه با ساير

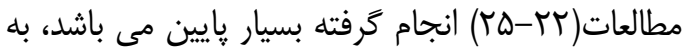
طورى كه مشخص شد كه أ/.9 درصد از افراد مورد

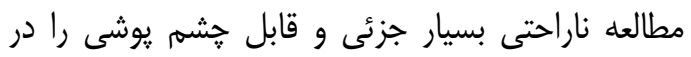
نواحى اسكلتى -عضلانى خود كزارش كردند. هم جنين / ا ع درصد از افراد داراى مشكل جزئى در سيسته اسكلتى-عضلانى خود بودند و درصد ناجيزى از افراد

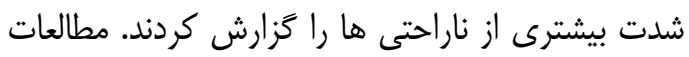

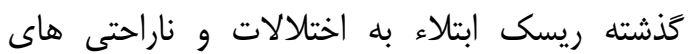
اسكلتى-عضلانى را بسيار بالاتر ززارش كرده اند. به

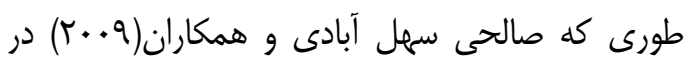
مطالعه خود نشان دادند كه ميزان شيوع اختان التالات

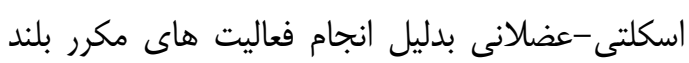
كردن دستى بار بالا مى باشد(ع). افزايش شيوع اختلالات و ناراحتى هاى اسكلتى-عضلانى باعث

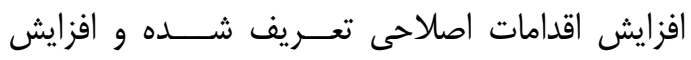

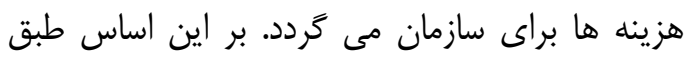
مطالعه حاضر به دليل اين كه شيوع ناراحتى هاى

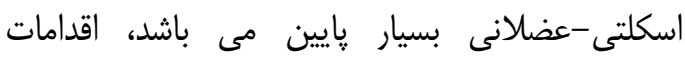

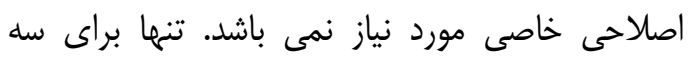

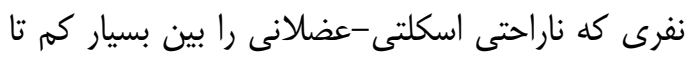
كمى زياد ززارش كردند، اقدامات اصلاحى و درمانى

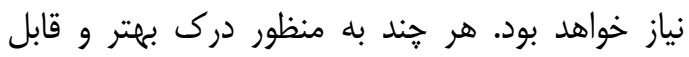
قبول بايستى طى سال هاى آينده ارزيابى دوباره صورت بخيرد و وضعيت كنونى در حد مطلوبى كه إنهاب مشاهده شده است حفظ شده و موارد نقص مشاهده شده اصلاح گردد و اثربخشى اقدامات كنترل گردد.

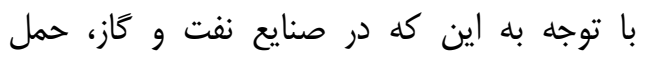

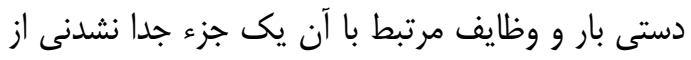
كار محسوب مى شود، بررسى و ارزيابى اين وظايف در

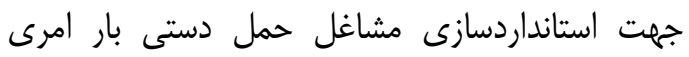

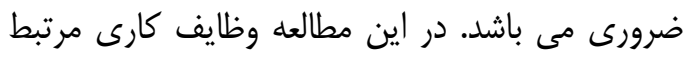

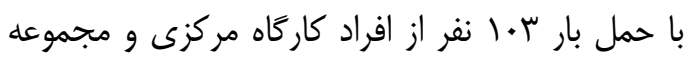
انبارهاى شركت يالايش نفت آبادان با استفاده از روش

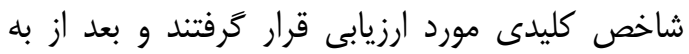

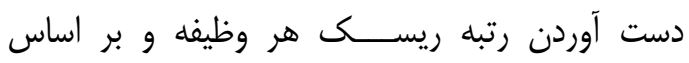

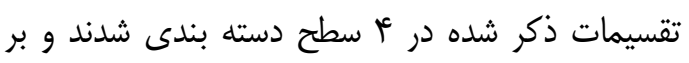

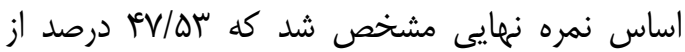




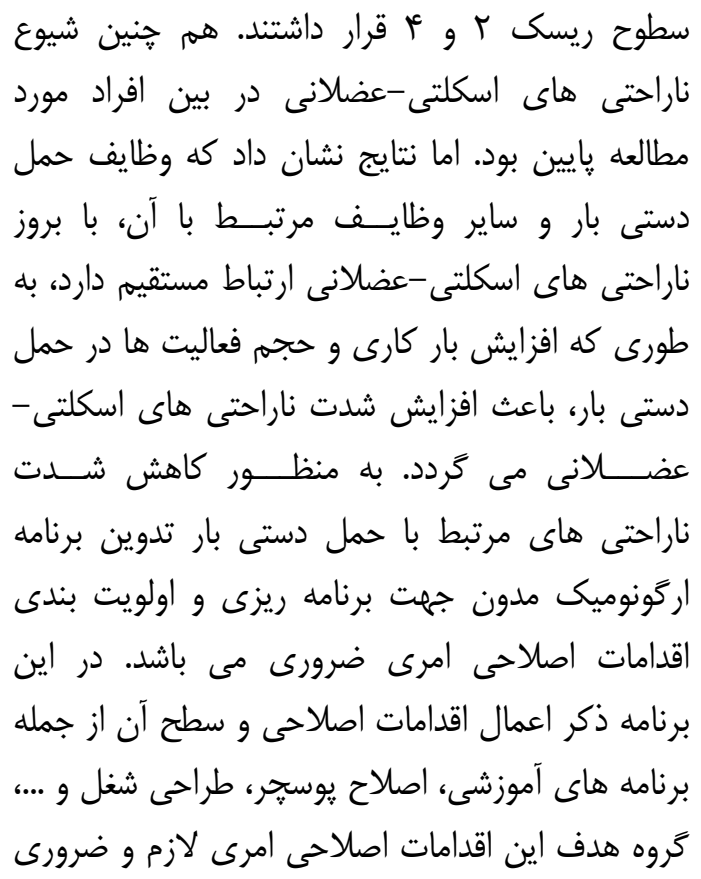

\section{References}

1.Long MH, Johnston V, Bogossian F. Work related upper quadrant musculoskeletal disorders in midwives nurses and physicians a systematic review of risk factors and functional consequences. Appl Erg 2012;43:455-67.

2.Osborne A, Blake C, Fullen BM, Meredith D, Phelan J, McNamara J, et al. Prevalence of musculoskeletal disorders among farmers: a systematic review. Am J Indus Med2012;55:143-58.

3.Eskandari D, Ghahri A, Gholamie A, MotalebiKashani M, GA M. [Prevalence of musculoskeletal disorders and work related risk factors among the employees of an automobile factory in Tehran during 200910]. Feyz J Kashan Uni Med Sci2011;14:539-45.(Persian)

4.Hesam G, Motamedzade M, khakbaz G, Moradpour Z. Ergonomics intervention in poultry slaughter industry and evaluate the effectiveness by key indicators method. J Erg2014;2:9-19.

5.Roffey DM, Wai EK, Bishop P, Kwon BK, Dagenais S. Causal assessment of workplace manual handling or assisting patients and low back pain: results of a systematic review. Spine J2010;10:639-51.

6.Martimo KP, Verbeek JH, Karppinen J, Furlan AD, Kuijer PPF, Viikari-Juntura E,

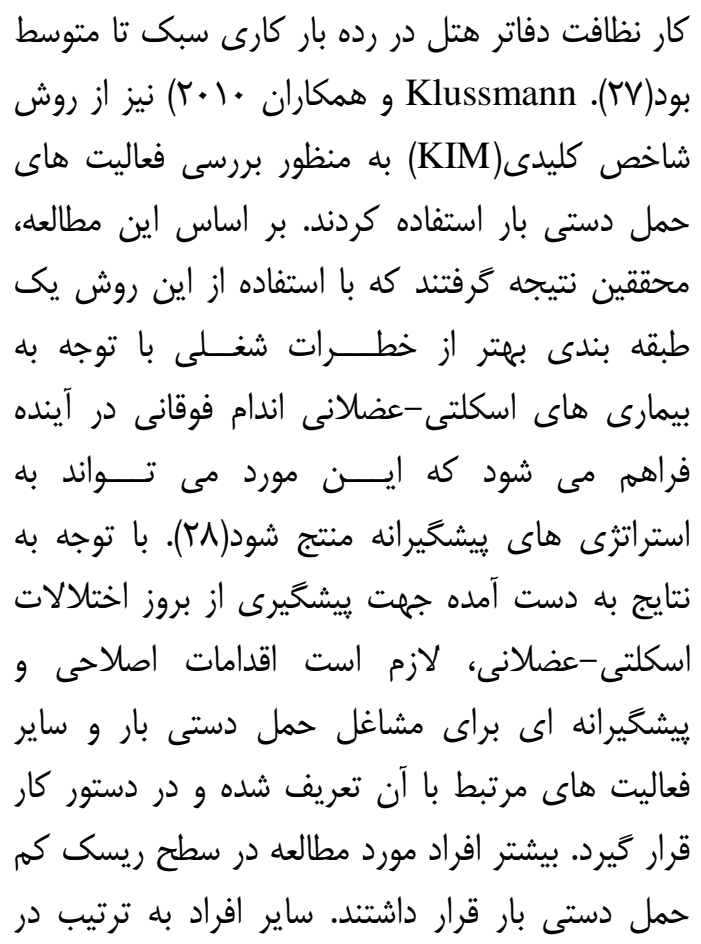

et al. Manual material handling advice and assistive devices for preventing and treating back pain in workers. Cochrane Lib 2007;22:134-9.

7.Lorusso A, Bruno S, Labbate N. A review of low back pain and musculoskeletal disorders among Italian nursing personnel. Industrial Health 2007;45:637-44.

8.Choobineh A, Tabatabaee SH, Behzadi M. Musculoskeletal problems among workers of an Iranian sugar-producing factory. Int $J$ Occup Safety Erg 2009;15:419-24.

9.Bültmann U, Franche RL, Hoggjohnson $\mathrm{S}$, Cote $\mathrm{P}$, Lee H, Severin C, et al. Health status work limitations and return to work trajectories in injured workers with musculoskeletal disorders. Qual Life Res 2007;16:1167-78.

10.Yeung SS, Genaidy A, Deddens J, Alhemood A, Leung P. Prevalence of musculoskeletal symptoms in single and multiple body regions and effects of perceived risk of injury among manual handling workers. Spine 2002;27:2166-72.

11.Carrivick PJ, Lee AH, Yau KK, Stevenson MR. Evaluating the effectiveness of a participatory ergonomics approach in reducing the risk and severity of injuries 
from manual handling.

Ergonomics2005;48:907-14.

12.Haslam C, Clemes SA, Mcdermott H, Shaw K, Williams C, Haslam R. Manual handling training investigation of current practices and development of guidelines. Appl Erg 2007;3:123-7.

13.Russell SJ, Winnemuller L, Camp JE, Johnson PW. Comparing the results of five lifting analysis tools. Appl Erg 2007;38:917.

14.Steinberg U, Caffier G, Liebers F. Assessment of manual material handling based on key indicators German guidelines. London Uni Publication. 2006;P.319-38.

15. The prevalence of musculoskeletal disorders and occupational risk factors in Kashan SAIPA automobile industry workers by key indicator method 1390. J Health Safet Work2012;2:27-36. (Persian) 16.Rieger MA. The key indicator method for manual handling operations evaluation of a new method for the assessment of working conditions within a cross sectional study. Occup Med 2010;4:22-7.

17.Suzaly N, Nowack T, Sprenger S, Kurtz P. An attempt to objectively determine part of the key indicator method using the Kinect camera. Appl Erg 2014;2:32-6.

18.Lin FY. Applicability of key indicator method for preventing musculoskeletal disorders in Taiwans industries. 2011.

19.Erdinc O, Hot K, Ozkaya M. Turkish version of the cornell musculoskeletal discomfort questionnaire cross cultural adaptation and validation. Work J Preve Assess Rehabil 2011;39:251-60.

20.Sethi J, Sandhu JS, Imbanathan V. Effect of body mass index on work related musculoskeletal discomfort and occupational stress of computer workers in a developed ergonomic setup .BMC Sports Sci Med Rehabil 2011;3:22.
21.Afifehzadeh-Kashani $\mathrm{H}$, Choobineh A, Bakand S, Gohari MR, Abbastabar H, Moshtaghi P. Validity and reliability Farsi version cornell musculoskeletal discomfort questionnaire. Iran Occup Health $\mathrm{J}$ Res 2011;7:10.

22.Walkerbone K, Palmer KT, Reading I, Coggon D, Cooper C. Prevalence and impact of musculoskeletal disorders of the upper limb in the general population. Arth Care Res 2004;51:642-51.

23.Chopra A, Abdelnasser A. Epidemiology of rheumatic musculoskeletal disorders in the developing world. Best Pract Res Clin Rheumatol2008;22:583-604. 24.David G, Woods V, Li G, Buckle P. The development of the quick exposure check for assessing exposure to risk factors for work related musculoskeletal disorders. Appl Erg 2008;39:57-69.

25.Janwantanakul P, Pensri P, Jiamjarasrangsri V, Sinsongsook T. Prevalence of self-reported musculoskeletal symptoms among office workers. Occup Med 2008;58:436-8.

26.Salehisahlabadi A, Naslsaraji G, Zeraati $\mathrm{H}$, Sharifian A. Assessment of spine curvatures cervical thoracic lumbar prevalence and their associations with musculo skeletal disorders in automobile industry workers. J Sch Publ Health Inst 2009;6:49-60.

27.Kalkis H, Roja Z, Kalkis V. Physical load analysis in hotel cleaning work. Agr Res 2014;12:843-50.

28.Klussmann A, Steinberg U, Liebers F, Gebhardt H, Rieger MA. The key indicator method for manual handling operations evaluation of a new method for the assessment of working conditions within a cross sectional study. BMC Muscul Disorders2011;2:9-14. 


\title{
Ergonomics Assessment of Manual Handling Tasks using the Key item Method (Kim) and its Relationship with Prevalence of Musculoskeletal Disorders in Abadan Oil Refinery
}

\author{
Akbari $\mathrm{J}^{1}$, Mousavikoti $\mathrm{M}^{2}$, Kazemi $\mathrm{M}^{3}$, Moradirad $R^{l^{*}}$
}

(Received: July 20, 2015

Accepted: January 7, 2017)

\begin{abstract}
Introduction: Manual handling tasks are considered to be the main causes of occupational back pains. Therefore, the assessment of manual handling tasks for the prevention of work musculoskeletal disorders (WMSDs) sounds necessary. The aim of this study was to assess the manual handling tasks using the key item method (Kim) and determine its relationship with the prevalence of musculoskeletal disorders using CMDQ tool in the workplace of the central workshop in Abadan oil refinery.
\end{abstract}

Materials \& Methods: This cross-sectional descriptive-analytical study was performed on 103 employees of Abadan's central workshop, using the simple sampling. Data were collected using KIM and CMDQ questionnaires and analyzed using Pearson and multiple linear regression tests in SPSS version 20.

Findings: Based on the results of the assessment by KIM method, 48 subjects were in the risk level 1,36 subjects in the risk level 2 and 19 subjects in the risk level 4. Also, based on the score of CMDQ questionnaire, 95 people were with very minor and negligible disorders, 4 cases with minor disorders, 1 person with very low disorders, 1 person with low disorders, one with medium disorders, and one with high disorders. In addition, the results of statistical tests showed a significant relationship between scores of KIM and WMSDs $(\mathrm{P}=0.002)$. However, there were no significant relationship between these two variables and demographic characteristics of individuals.

Discussion \& Conclusions: Our investigation demonstrated that manual handling tasks and other tasks related to it have a direct relationship with the incidence of WMSDs; so that, the increase in the workload and nature of the manual handling tasks will enhance the severity of WMSDs. In order to reduce the severity of such disorders, corrective measures such as training programs, posture modifications, and job designs seem necessary.

Keywords: manual material handling, workrelated musculoskeletal disorders, Key Item Method, oil-refining industry

1. Industrial OccupationalHealth Administration, Abadan Oil Refining CO, Iranian National Oil Refining and Distribution Company, Abadan, Iran

2. Dept of Occupational Health, Faculty of Health, Tehran Universityof Medical Sciences, Tehran, Iran

3. Dept of Occupational Health, Faculty of Health, Ilam University of Medical Sciences, Ilam, Iran

* Corresponding author Email: r.moradi50@yahoo.com 